\title{
Evaluation of Land Cover Classification Based on Multispectral versus Pansharpened Landsat ETM+ Imagery
}

\author{
Ko Ko Lwin and Yuji Murayama \\ Division of Spatial Information Science \\ Graduate School of Life and Environmental Sciences \\ University of Tsukuba \\ 1-1-1 Tennodai, Tsukuba, Ibaraki 305-8572 Japan
}

Phone: +81(29) 853-4211, Fax: +81(29) 853-4211

Email: kokolwin@geoenv.tsukuba.ac.jp

\begin{abstract}
Land cover generated from satellite images is widely used in many real-world applications such as natural resource management, forest type mapping, hydrological modeling, crop monitoring, regional planning, transportation planning, public information services, etc. Moreover, land cover data are one of the primary inputs to many geospatial models. In SouthEast Asia's cities where the houses are interspersed with small trees, bare land and grassland are difficult to detect in multispectral Landsat ETM+ images because its 30 × $30 \mathrm{~m}$ spatial resolution is likely to capture a variety of land cover within each pixel, particularly in urban areas. Although other medium resolution multispectral satellites such as ALOS, SPOT, IRS, and so on have higher spatial resolution than Landsat ETM+, it is sometimes difficult to extract the built-up or human settlement areas because of the lack of shortwave infrared bands which are very useful for distinguishing between soil and vegetation. In this paper, we generated land cover data from both Landsat ETM+ multispectral and pansharpened images by applying the same training areas but using different spectral properties. We differentiated between two classified images visually, spectrally and spatially. Our results showed that $65 \%$ of the total area had similar land cover and 35\% had dissimilar land cover. Although dense urban areas, forest, agricultural land and water were almost the same in the classified images, sparse urban areas and grassland were quite different. Much of the sparse urban area were detected using the pansharpened classified imagery. This is important in South-East Asian cities where many houses are mixed with trees or grassland. Accurate delineation of human settlement area plays a critical role in population estimation, socio-economic studies, disaster management and regional development planning.
\end{abstract}


Keywords: Landsat ETM+, Multispectral, Pansharpened, Land cover classification, Accuracy assessment, Ground reference information points

\section{Introduction}

Land cover classification is one of the data processing steps applied to remote sensor data to extract information from multispectral satellite images such as Landsat MSS/TM/ETM+, ALOS, SPOT, ASTER, etc. Land cover from satellite-generated data are widely used in natural resources management, environmental studies and urban and regional planning. Some applications are forest type mapping (Kennaway and Helmer 2007), forest fire assessment (Mitchell and Fei 2010), Vegetation Drought Response Index (VegDRI) mapping (Brown et al. 2008), surface water estimation, land resource assessment and urban green space delineation (Lwin and Murayama 2011). Moreover, land cover is one of the primary forms of input data in many geospatial models and spatial decision-support systems. In addition, remote sensing data used in human settlement mapping are important for developing countries where fine-scale GIS data are difficult to obtain. Human settlement mapping especially the detection of sparse urban, dense, industrial and built-up infrastructures are important for population estimation, country resource assessment, urban planning and monitoring of urban growth and disaster management. Many studies have used remote sensing data related to human settlement such as house value estimation (Jensen et al. 2004), population estimation (Yuan et al. 2008; Wu and Murray 2005; Liu and Herold 2006; Mao et al. 2012), slum detection (Weeks et al. 2007; Kit et al. 2012; Kohli et al. 2012), urban population density modeling (Joseph et al. 2012), leaf index and household energy (Jensen et al. 2003), life quality assessment (Jensen et al. 2004; Nichol and Wong 2006, chap.12; Li and Weng 2007), urban growth (Ward et al. 2000; Phinn et al. 2002; Cheng and Masser 2003) and social vulnerability assessment (Rashed et al. 2007, chap. 9; Taubenböck et al. 2008).

Because of limited data storage capacity onboard satellites and transmission time, many earth resource satellites were designed to install a high-resolution band described as panchromatic along with multiple low-resolution bands described as multispectral. The algorithms fusing these two images are described as pansharpening, and they combine the spatially detailed structure of a high-resolution panchromatic image with the high spectral information of a lower-resolution multispectral image to produce a high-resolution multispectral image (Klonus and Ehlers 2007; Haack and Herold 2007; Lu and Weng 2007). Pansharpened images generally improve visual interpretation and quantitative analysis (Klonus and Ehlers 2007; Lu and Weng 2007). Therefore pansharpening processes play a critical role in remote 
sensing and evaluation of these pansharpened images in various applications is required. Until now, many pansharpened images were utilized for visualization purposes in GIS applications as a basemap. Although many data fusion algorithms have been proposed and evaluated for visualization purposes, there are still none which evaluate other remote sensing applications such as land cover classification, forest type mapping, vegetation indexing, wetland delineation, water quality assessment and so on. In the case of Landsat ETM+, the $30 \times 30 \mathrm{~m}$ spatial resolution in multiple spectral bands is likely to contain a variety of land covers particularly in the urban areas (Jensen and Cowen 1999) in cities in developing countries where the houses are interspersed with trees or bare land. This will introduce errors in socio-economic studies, disaster management and population estimation. Therefore, classified multispectral pansharpened images could possibly reduce these errors and improve the accuracy of socioeconomic studies performed using remote sensing data.

The main objective of this study was to evaluate classified Landsat ETM+ multispectral and pansharpened images by applying the well-known data fusion method, principle component analysis (PCA), in order to use them in human settlement mapping in developing countries. Moreover, Landsat ETM+ imagery has many advantages because of its favorable moderate spatial resolution for thematic mapping and a wide range of spectral properties from visible to short-wave infrared. In this paper, we used the PCA fusion method to generate pansharpened images in order to maintain the original spectral properties of the multispectral bands (Band 6 omitted) for supervised classification and many commercial image processing vendors provide the PCA image generation. We classified both multispectral and pansharpened images using the same training areas but in using different spectral properties. Finally, we evaluated two classified images visually, spectrally and spatially. Many classification accuracy assessment studies are based on Kappa statistics which normally do not take into the account spatial patterns and spatial contiguity. Therefore, in this study we used additional Anselin Local Moran's I and Z scores to evaluate the classified images in terms of the spatial patterns and spatial contiguity between two images.

\section{Methodology}

\subsection{Study area and data}



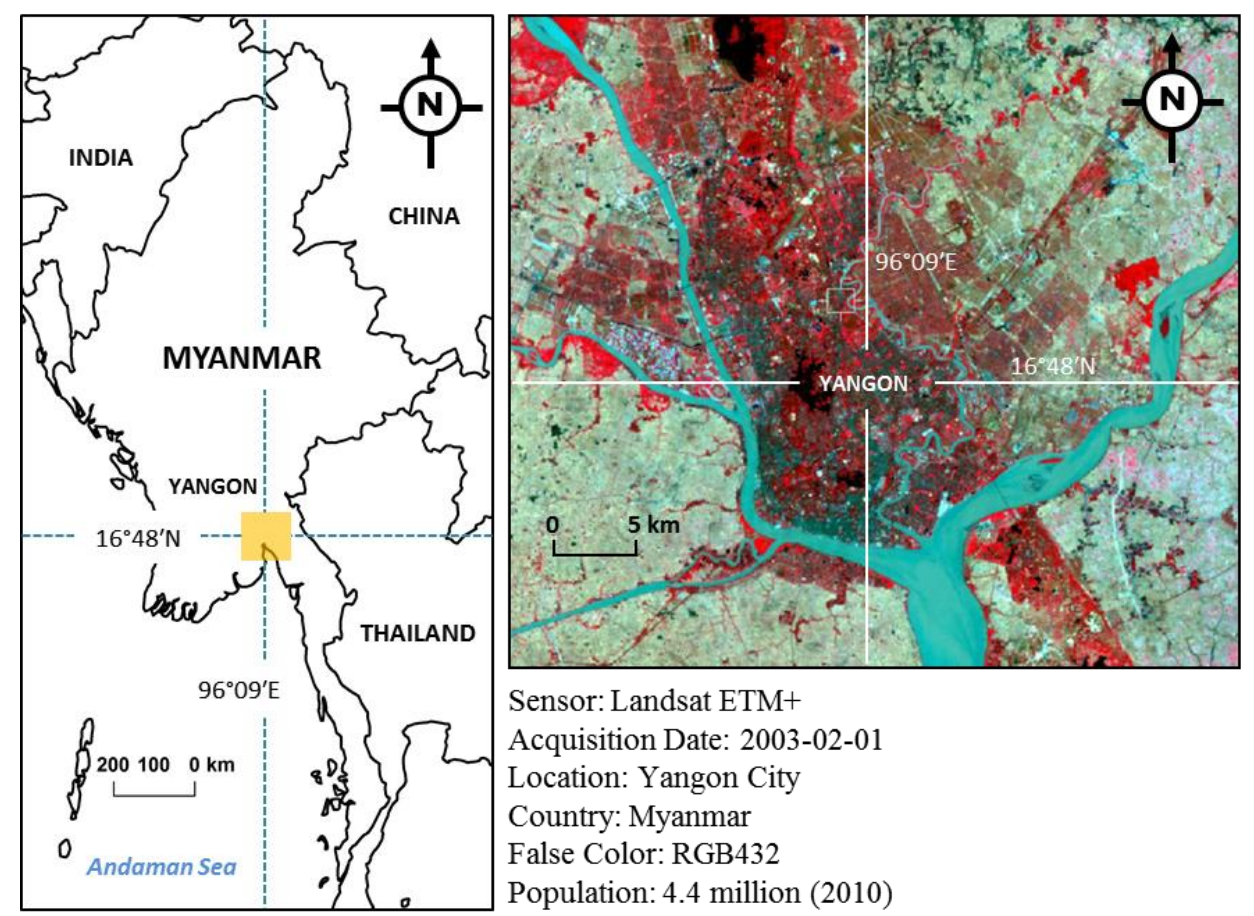

Figure 1. Study area and description of Landsat ETM+ image.

The study area is Yangon City, in the south of Myanmar (Figure 1), with a population of about 4.4 million (2010). The city is composed of various land cover types, forest, rivers, lakes, industrial zones, agricultural land, dense and sparse urban land, grassland and bare land. Figure 2 shows the overall research flow in this study. In this research, we used Landsat ETM+ imagery. All images are pre-processed images which have been atmospherically and geometrically corrected. We used ERDAS Imagine remote sensing software to produce the pansharpened images using the PCA fusion algorithm and then stretched the data to Unsigned 8bit. 


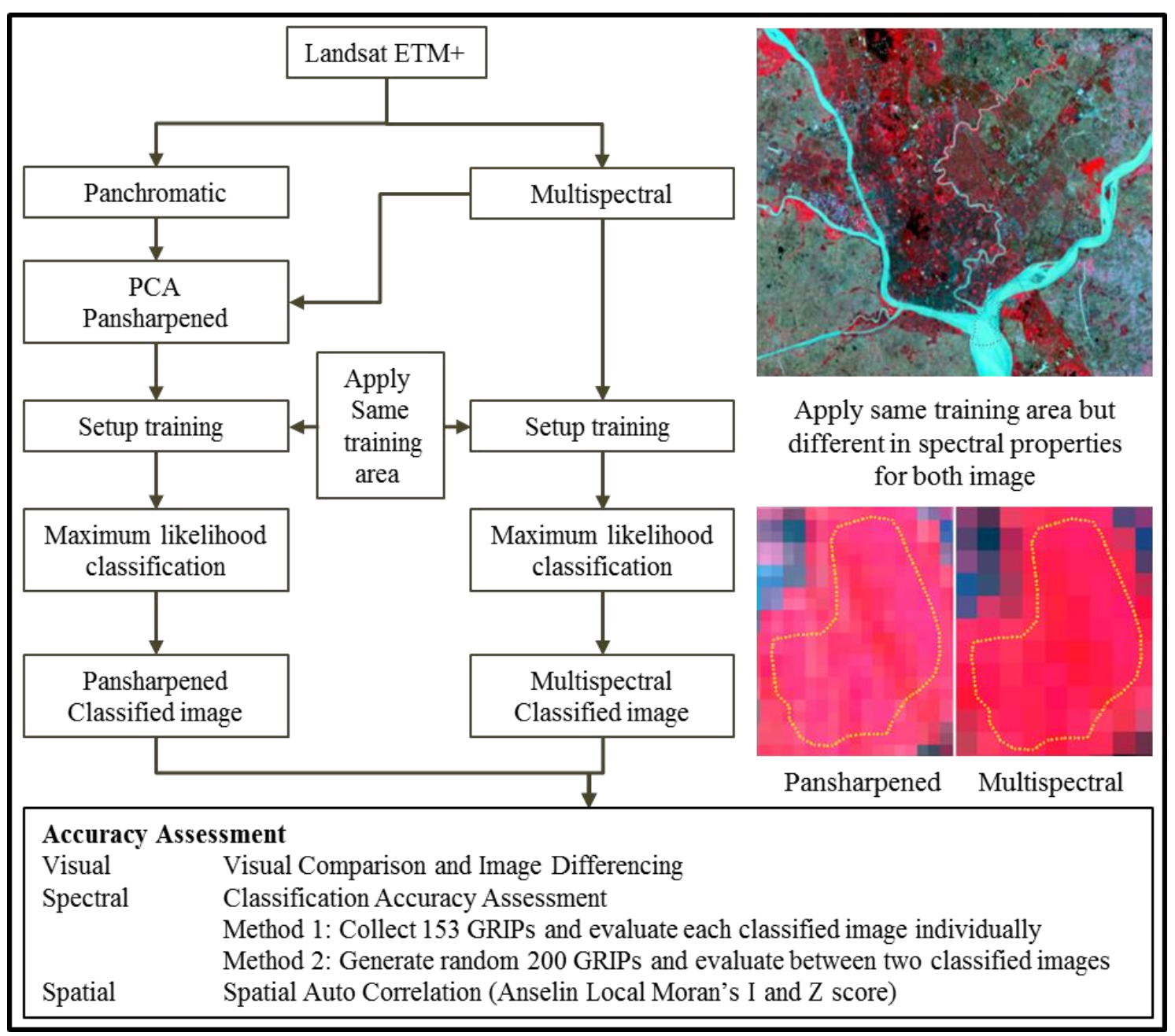

Figure 2. Research flow.

\subsection{PCA-based image fusion}

Different data fusion methods have been proposed in the literature: principal component analysis, intensity-hue-saturation (IHS) transforms, Brovey transforms, multiplicative transforms and wavelet transforms. Some of these methods have been compared for the fusion of ETM+ PAN and MS data (Vaiopoulos et al. 2001; Nikolakopoulos 2003) and commercial remote sensing software provided most of the algorithms. Among them is the principle component analysis (PCA) fusion method for generating PS images in order to maintain the original number of MS bands (Band 6 omitted) for supervised classification. PCA is a statistical approach based on eigenvectors and values which maintains the key features in the original image while reducing the noise level. PCA converts inter-correlated MS bands into a new set of uncorrelated components. The first component typically resembles a PAN image. It is, therefore, replaced by high-resolution PAN band for image fusion. The PAN image is fused into the low-resolution MS bands by a reverse PCA transform (Zhang 2004). PCA is designed to 
reduce a large set of variables to a small set that still contains most of the information available in the larger set. The PCA technique enables the creation and use of a reduced set of variables, which are called principal factors. A reduced set is much easier to analyze and interpret. Figure 3 compares the original multispectral image (left) and pansharpened image (right) at RGB $=653$ combination. Urban sparse areas are much clearer in the pansharpened image and distinguish between soil and vegetation thanks to the presence of shortwave infrared regions.

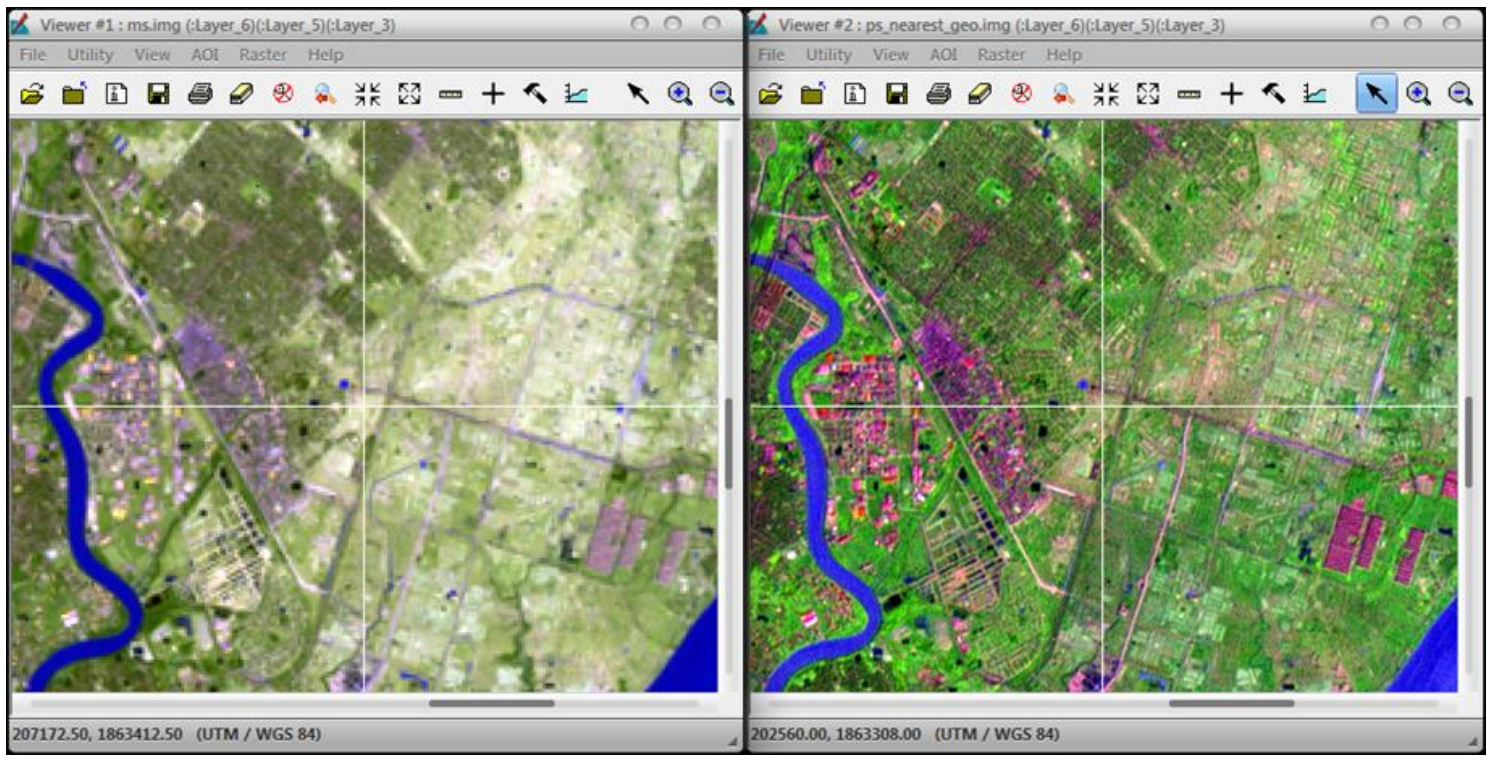

Figure 3. Original multispectral image (left) and PCA-based pansharpened image (right) at RGB $=653$ combination.

\subsection{Classification scheme}

We acquired Landsat ETM+ images in the harvest period, winter season (1 February 2003). Therefore, in this classified image, agricultural land may include crop land, barren land and other farmland. During the rainy season between June and October, these agricultural lands are filled with paddy fields and are difficult to distinguish from grasslands. Moreover, it is very difficult to obtain cloud-free images during the rainy season. We used supervised classification for both the multispectral and pansharpened images and collected signatures from the pansharpened images thanks to visual landscape characteristics which were easier to identify than those found in the multispectral images. For classification, the same signatures of the AOIs were used for both images because we wanted to keep the same area but analyze different spectral properties.

We collected a total 17 training samples: W1, W2, W3, W4, W5, F1, F2, F3, F4, F5, A1, A2, A3, A4, U1, U2, and U3, to classify the images. We collected training samples for every different land cover type and classified the image. Later we merged the land cover classes 
into six major classes: water, forest, grassland, agricultural land, sparse and dense urban land (Figure 4). For example, we collected training samples from various surface waterbodies such as shallow water, deep water, lake water, small ponds and turbid water and assigned them to W1 to W5. F1 to F5 were collected from various forest and grassland covers and A1 to A5 were collected from paddy fields, dry land and other man-made infrastructures like playgrounds, airports, etc. Training samples from dense urban pixels (i.e., downtown) were assigned to U1 and urban area patches with vegetation and industrial zones were assigned to U2 and U3, respectively. We applied the parallelepiped rule for non-parametric signatures and the maximum likelihood classifier algorithm for parametric signatures. The maximum likelihood classifier is still one of the most popular methods of classification in remote sensing whereby a pixel with the maximum likelihood is classified into the corresponding class. Figure 4 shows the various land cover types in the study area from high-resolution satellite images.

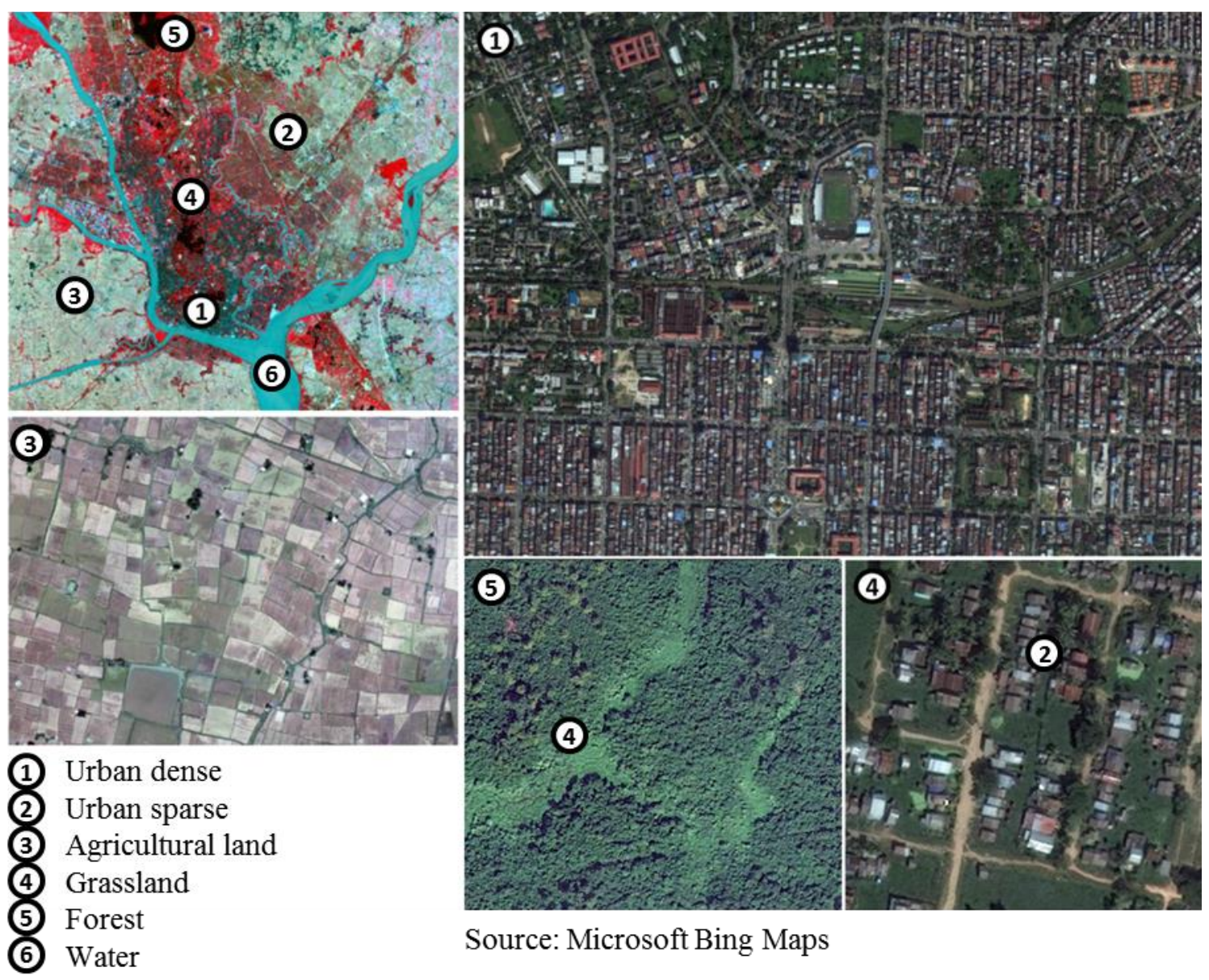

Figure 4. Various land cover types in the study area from high-resolution satellite images. 


\subsection{Evaluation Approaches}

We distinguished between classified pansharpened and multispectral images visually, spectrally and spatially.

\subsubsection{Visual Assessment}

We performed visual comparison and image differencing methods to evaluate two classified images visually and quantitatively.

\section{(1) Visual comparison}

Visual comparison or interpretation is the first step in remote sensing data processing. We compared two classified images with high-resolution satellite imagery using the ERDAS Imagine view link function (Figure 5). 


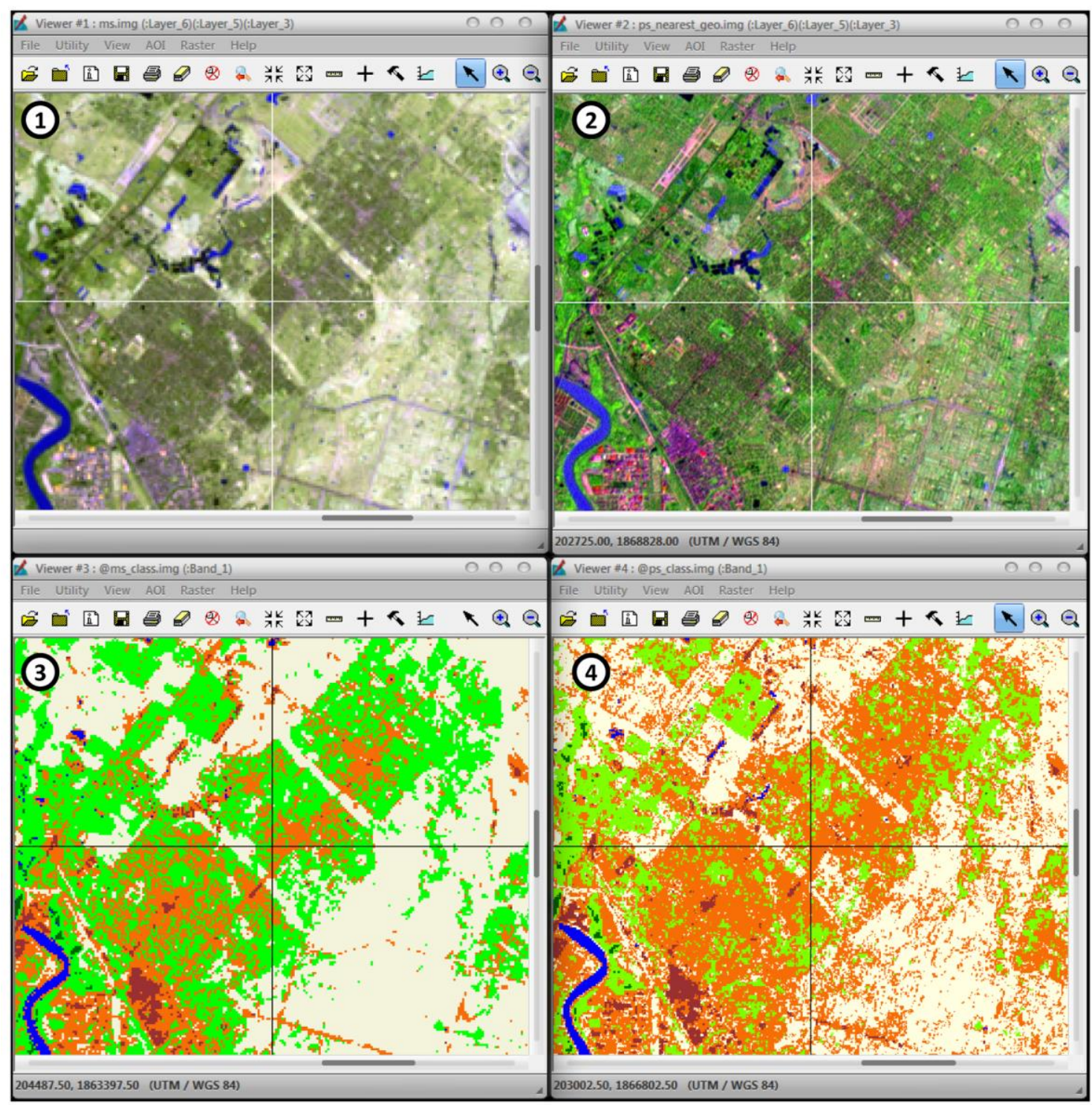

\begin{tabular}{|c|c|}
\hline Land Cover & Image at $30 \mathrm{~m}(\mathrm{RGR}=653)$ \\
\hline Urban dense & ctral Image at $30 \mathrm{~m}(\mathrm{RGB}=653)$ \\
\hline Urban sparse & (2) PCA based pansharpened image at $15 \mathrm{~m}(\mathrm{RGB}=653)$ \\
\hline Agricultural land & \\
\hline Grassland & (3) Multispectral classified image at $30 \mathrm{~m}$ \\
\hline Forest & \\
\hline Water & (4) Pansharpened classified image at $15 \mathrm{~m}$ \\
\hline
\end{tabular}

Figure 5. Visual assessment by means of spatial linking between two classified images and high-resolution satellite images (the urban sparse pixels in the pansharpened classified image are higher than in the multispectral classified image)

\section{(2) Image differencing}

We used image differencing methods to assess two classified images quantitatively since the primary purpose of remote sensing data is to quantify land cover, vegetation intensity 
or surface temperature. We performed quantitative analysis of two classified images. This analysis measures how much of the classified image has similar or dissimilar land cover rather than classification accuracy. Image differencing allows us to evaluate the overall percentage of similarity and dissimilarity between two classified images (Figure 7).

\subsubsection{Classification accuracy assessment}

Two accuracy assessment approaches were performed for both classified images. One collected 153 image-based ground reference information points (GRIPs) to assess the two classified images individually and another accuracy assessment generated 200 random points on both images and matched their land covers.

\section{(1) Image-based ground reference information points collection}

Many land cover classification accuracy assessments involve ground-refernce data collection. Ground reference data can be acquired by field investigation with handheld GPS, using high spatial resolution satellite images or air photos and questionnaire surveys of local people. This approach has some limitations, such as GPS accuracy, time differences and accessibility issues. For example, the accuracy of a handheld GPS can vary several meters depending on various landscape characteristics such as open space, semi-open space and closed space (i.e., forest and high-rise buildings). The time difference is another issue in collecting ground reference data for the past 10 or 15 years necessary for land cover change analysis. Although the time difference issue can be solved by using past high-resolution aerial photos and questionnaire surveys of native or local people for validation purposes, some land cover classes, such as dense forest, lakes and rivers, are difficult to access and collecting ground reference data is time-consuming. Today's web-based high-resolution satellite images, which are available around the world, such as Google Map/Earth and Microsoft Bing Maps, allow geospatial users to collect GRIPs in a timely manner for general land use types such as water, forest, grassland, crop land and urban areas in natural color (i.e., RGB-321). Ground reference data collection is still required, however, for detailed land cover type classification, such as forest into evergreen forest, deciduous forest, bamboo forest, and so on because some land covers are difficult to discriminate in natural color mode.

In this study, we collected 153 ground reference information points (water $=43$, forest $=9$, grassland $=29$, agricultural land $=31$ urban sparse $=30$ and urban dense $=11)($ Table 1$)$ from a high-resolution Google Earth/Map integrated with original multispectral and pansharpened images based on spectral properties and knowledge of the study area. Although Google Earth/Map has much detailed and recent ground information, our classified image was 
ten years old. Therefore, we needed carefully to collect GRIPs at the permanent land covers between Google Earth/Map and our satellite image. Moreover, in the satellite imagery, different band combinations allowed the discrimination of various land cover types. For example, lake water shows as dark blue and turbid water shows as bright blue in the RGB-543 band combination in Landsat TM/ETM+; dense forest shows as reddish and grassland as orange or pale red in the RGB 432 band combination. We computed an error matrix and Kappa statistics between GRIPs and classified multispectral and pansharpened images individually. An error matrix was created and used to assess user's and producer's accuracies (Story and Congalton 1986) for each land cover. User's accuracy is useful for spatial analysis purposes because the accuracy assessment is carried out point-to-point or row-by-row, whereas producer's accuracy is useful for the overall accuracy assessment of the classified image. Tables 1 and 2 show the error matrices and Tables 3 and 4 show the Kappa statistics of both classified images.

\section{(2) Accuracy assessment of two classified images}

An accuracy assessment was made of two classified images by generating 200 random ground reference information points and matching the land covers between two classified images. Table 5 shows the error matrix and Table 6 shows the Kappa statistics for the two images.

\subsubsection{Spatial Assessment}

\section{(1) Spatial assessment using spatial autocorrelation method}

Foody (1992) argues that the Kappa coefficient may be misleading because it is derived from the row and column margins, which include actual as well as chance agreement. Most accuracy assessment methods are based on statistical approaches, for example, user's and producer's accuracy, and the Kappa coefficient does not take into the account the spatial patterns and spatial contiguity which evaluate the characteristics of spatial units that are connected. These units share one or more characteristics with adjacent units and form a group. Pontius and Millones (2011) also provide very compelling reasons for abandoning Kappa as it gives redundant or misleading information. They recommend that the error matrix is summarized by the use of two much simpler summary parameters: quantity disagreement and allocation disagreement. To perform accuracy assessments of geospatial data, such as land cover, we need to include not only positions but also associated attribute information (i.e., water, forest, urban, etc.), referred to as spatial contiguity.

In this research, we used the spatial autocorrelation method to analyze and compare the spatial distribution patterns of both classified images. There are several ways of performing 
spatial autocorrelation; the most popular are Global Moran's I, Local Anselin Moran's I and Geary's C methods. We used Local Anselin Moran's I to assess whether two classified images had similar spatial distribution patterns. The local Moran test (Anselin 1995) detects local spatial autocorrelation. It can be used to identify local clusters (regions where adjacent areas have similar values) or spatial outliers (areas distinct from their neighbors). The Local Moran statistic decomposes Moran's I into contributions for each location i, expressed as $I_{i}$. The sum of $I_{i}$ for all observations is proportional to Moran's I, an indicator of global patterns. Thus, there can be two interpretations of Local Moran statistics, I as indicators of local spatial clusters (i.e., clustered, random or disperse) and $\mathrm{Z}$ scores indicating that the surrounding features have similar or dissimilar attribute values. Although this assessment does not measure classification accuracy, it does measure land cover similarities or dissimilarities in spatial patterns between two classified images, similarly to the previous image differencing method. We can also apply this approach to assess classification accuracy between GRIPs and classified images. We generated 3000 random points and collected land covers from both images. Then we measured Local Anselin Moran's I and Z scores. Here we used random points for spatial accuracy assessment unlike the previous stratified sampling method which is used for classification accuracy assessment.

\section{Results and Discussion}

Figures 6 and 7 show the results of both the multispectral and the pansharpened classified images. We observed that most land cover classes are very similar in both classified images, with the exception of urban sparse and grasslands. Road patterns, boundaries of rivers, lakes and small houses are more clearly distinguishable, however, in the pansharpened classified images. Small houses mixed with trees and paddy fields are also distinguishable in the pansharpened classified images. 


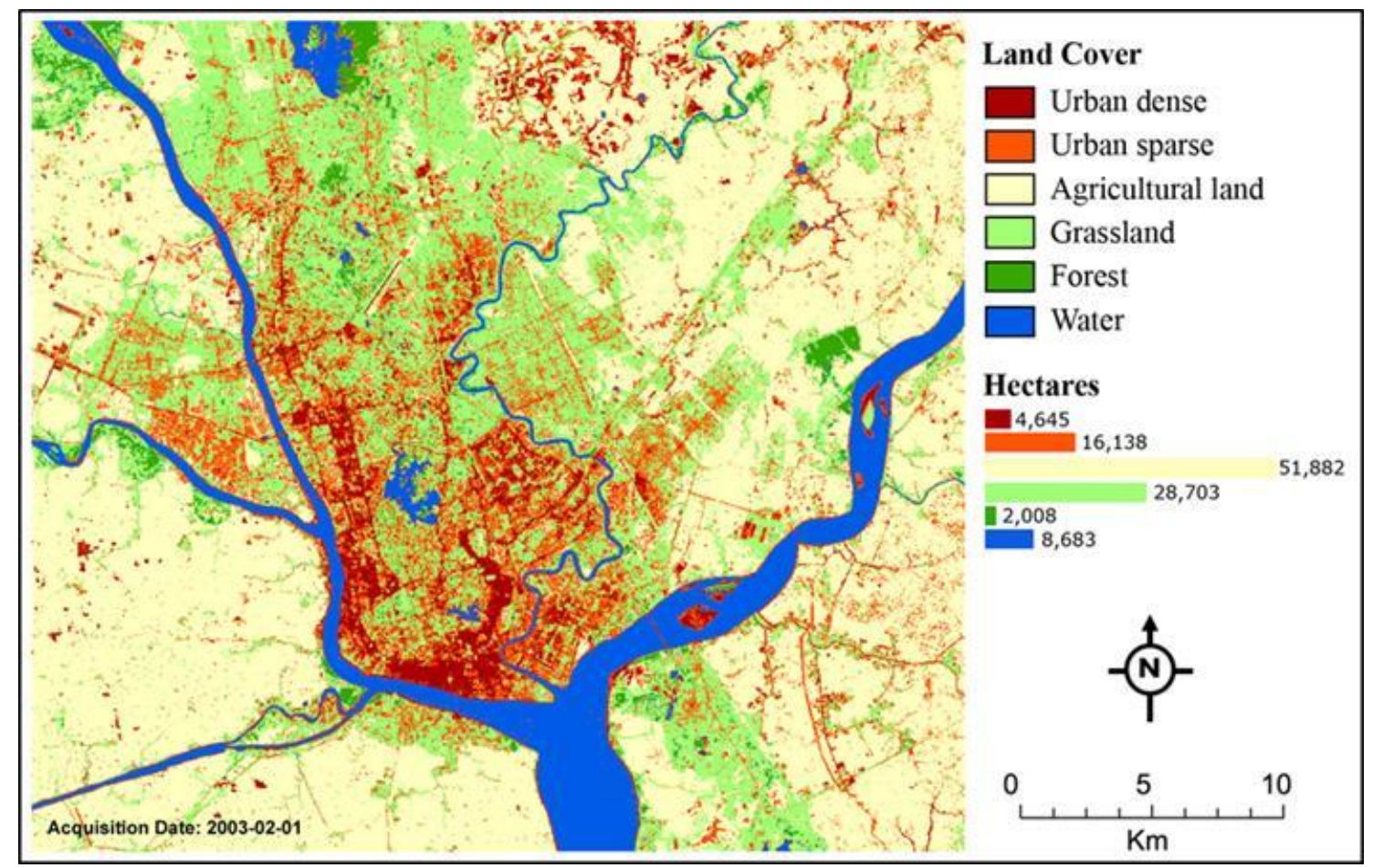

Figure 6. Classified Landsat multispectral image (spatial resolution at 30m).

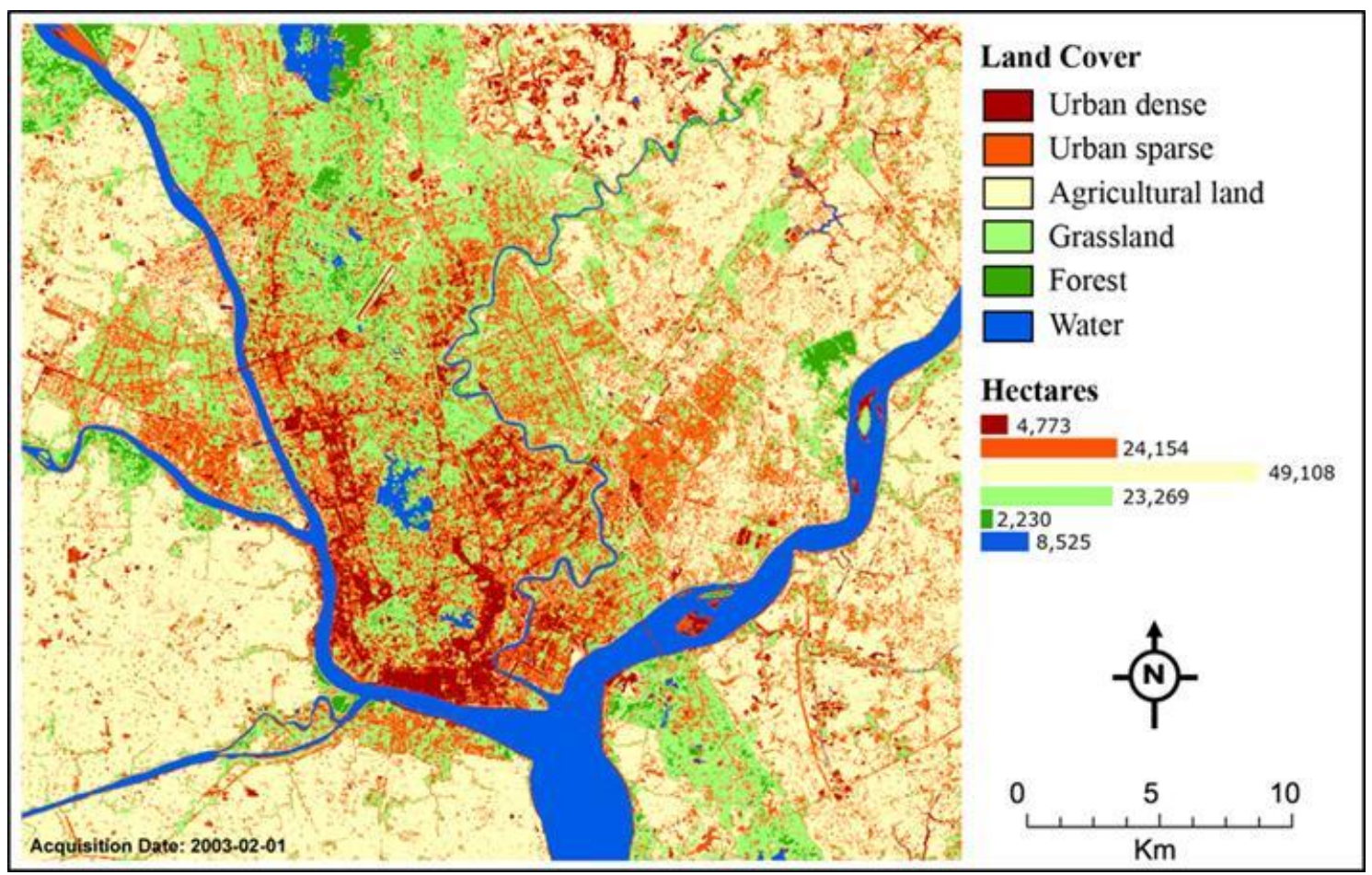

Figure 7. Classified Landsat pansharpened image (spatial resolution at $15 \mathrm{~m}$ ).

Figure 7 compares the area of each land cover in both classified images. The analysis shows that $65 \%$ of the study area has the same land cover and $35 \%$ has dissimilar. The left bar chart (Figure 7) shows the quantitative comparison of each land cover. Although water, forest 
and urban dense areas are classified as being of similar quantity, urban sparse and grassland areas are significantly different between the two images. Urban sparse areas are greater in the pansharpened classified image and grassland areas are greater in the multispectral classified image. In this case, the $30 \mathrm{~m}$ multispectral image is unsuitable for delineating the urban sparse category. Accurate identification of urban sparse areas is important for population estimation and disaster management.

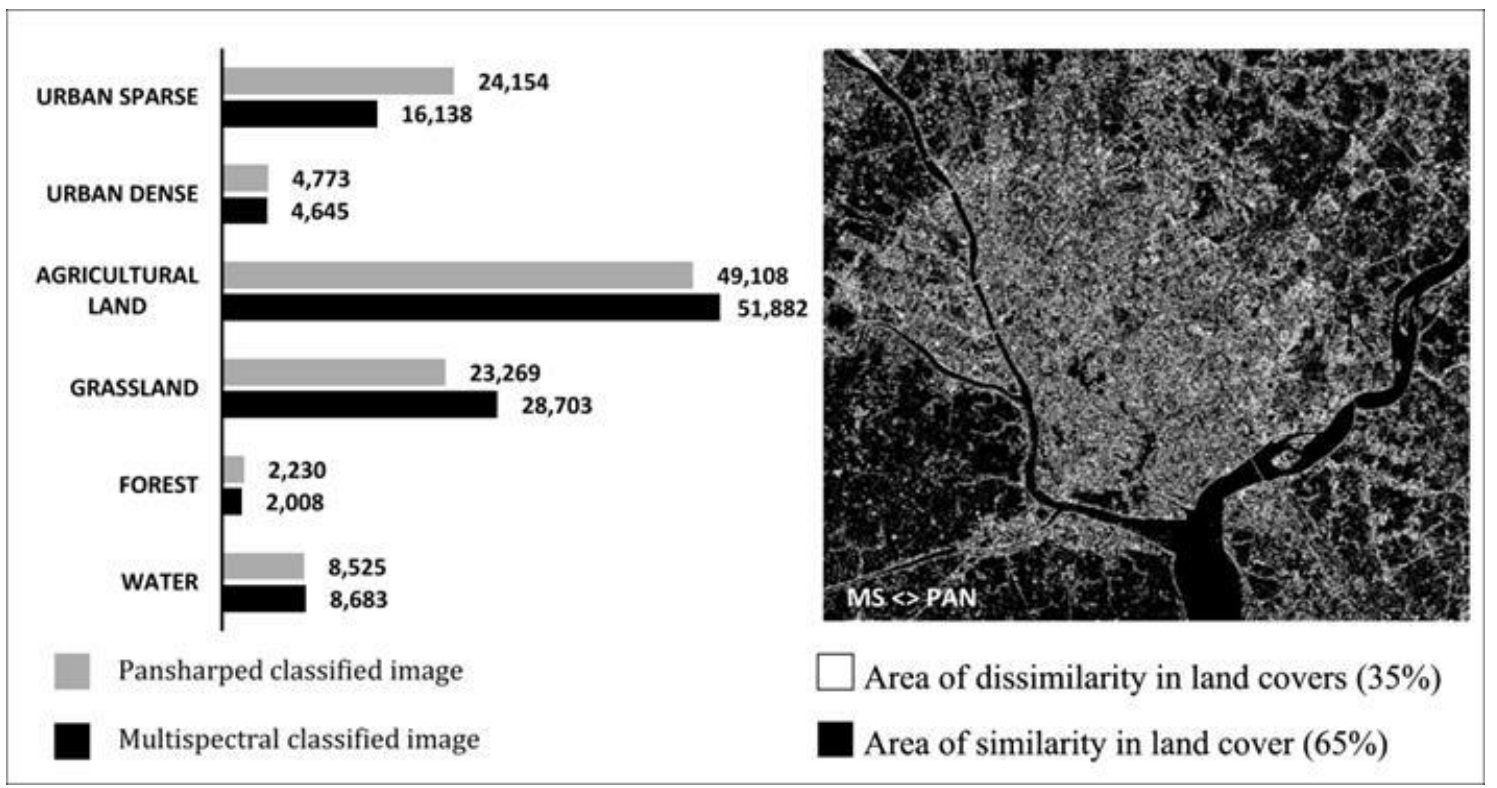

Figure 8. Quantitative assessments of two classified images (units are in hectares).

Tables 1 and 2 show the error matrixes of both classified images and * values are missed classified pixels. In this assessment, the overall classification accuracy for the multispectral image is $80.39 \%$ and the Kappa coefficient is 0.7566 (Table 3). The overall accuracy of the pansharpened image is $81.05 \%$ and the Kappa coefficient is 0.7646 (Table 4).

Table 1. Error matrix for the multispectral classified image and ground reference information points.

\begin{tabular}{cccccccc}
\hline \multicolumn{7}{c}{ ERROR MATRIX (MULTISPECTRAL VS. GROUND REFERENCE INFORMATION POINTS) } \\
\hline & WATER & FOREST & GRASSLAND & AG. LAND & URBAN (S) & URBAN (D) & Total \\
\hline WATER & 43 & 0 & 0 & 0 & 0 & 0 & 43 \\
FOREST & 0 & 9 & $16^{*}$ & 0 & 0 & 0 & 25 \\
GRASSLAND & 0 & 0 & 13 & 0 & 0 & $1^{*}$ & 14 \\
AG. LAND & 0 & 0 & 0 & 31 & 0 & $5^{*}$ & 36 \\
URBAN (S) & 0 & 0 & 0 & 0 & 26 & $4^{*}$ & 30 \\
URBAN (D) & 0 & 0 & 0 & 0 & $4 *$ & 1 & 5 \\
\hline Total & 43 & 9 & 29 & 31 & 30 & 11 & 153 \\
* = Missed classified pixels & & & & &
\end{tabular}


Table 2. Error matrix of pansharpened classified images and ground reference information points.

\begin{tabular}{cccccccc}
\hline \multicolumn{7}{c}{ ERROR MATRIX (PANSHARPENED VS. GROUND REFERENCE INFORMATION POINTS) } \\
\hline & WATER & FOREST & GRASSLAND & AG. LAND & URBAN (S) & URBAN (D) & Total \\
\hline WATER & 42 & 0 & 0 & 0 & 0 & 0 & 42 \\
FOREST & 0 & 9 & $13^{*}$ & 0 & 0 & 0 & 22 \\
GRASSLAND & 0 & 0 & 16 & 0 & 0 & $1 *$ & 17 \\
AG. LAND & 0 & 0 & 0 & 30 & 0 & $4 *$ & 34 \\
URBAN (S) & 0 & 0 & 0 & 0 & 26 & $5 *$ & 31 \\
URBAN (D) & $1^{*}$ & 0 & 0 & $1^{*}$ & $4 *$ & 1 & 7 \\
\hline Total & 43 & 9 & 29 & 31 & 30 & 11 & 153 \\
\hline * Missed classified pixels & & & & & &
\end{tabular}

Table 3. Accuracy assessment and Kappa statistics of multispectral classified image and ground reference information points.

\begin{tabular}{ccccccc}
\hline \multicolumn{7}{c}{ ACCURACY ASSESSMENT AND KAPPA (K^) STATISTICS (MULTISPECTRAL VS. GROUND REFERENCE INFORMATION } \\
POINTS) \\
\hline $\begin{array}{c}\text { Reference } \\
\text { Totals }\end{array}$ & $\begin{array}{c}\text { Classified } \\
\text { Totals }\end{array}$ & $\begin{array}{c}\text { Number } \\
\text { Correct }\end{array}$ & $\begin{array}{c}\text { Producer's } \\
\text { Accuracy }\end{array}$ & $\begin{array}{c}\text { User's } \\
\text { Accuracy }\end{array}$ & KAPPA (K^) STATISTICS \\
\hline WATER & 43 & 43 & 43 & $100 \%$ & $100 \%$ & 1.0000 \\
FOREST & 9 & 25 & 9 & $100 \%$ & $36 \%$ & 0.3200 \\
GRASSLAND & 29 & 14 & 13 & $45 \%$ & $93 \%$ & 0.9119 \\
AG. LAND & 31 & 36 & 31 & $100 \%$ & $86 \%$ & 0.8258 \\
URBAN (S) & 30 & 30 & 26 & $87 \%$ & $87 \%$ & 0.8341 \\
URBAN (D) & 11 & 5 & 1 & $9 \%$ & $20 \%$ & 0.1380 \\
\hline Total & 153 & 153 & 123 & & \\
\hline Producer's Accuracy = (Number Correct / Reference Total * 100) & \\
User's Accuracy = (Number Correct / Classified Total * 100) \\
Overall Classification Accuracy = 80.39\% \\
Overall Kappa Statistic = 0.7566
\end{tabular}

Table 4. Accuracy assessment and Kappa statistics of pansharpened classified image and ground reference information points.

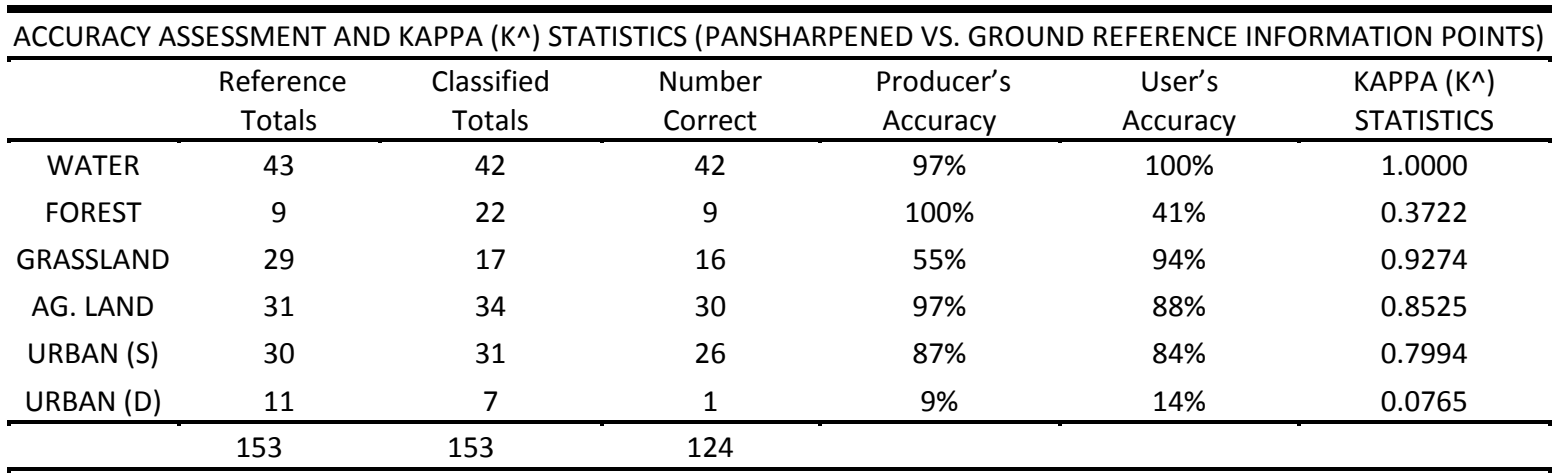

Producer's Accuracy $=$ (Number Correct / Reference Total $* 100)$

User's Accuracy $=($ Number Correct $/$ Classified Total $* 100)$

Overall Classification Accuracy $=81.05 \%$ 
Table 5 shows the error matrix of the multispectral and pansharpened classified images and Table 6 shows the producer's and user's accuracies and the Kappa coefficient for each land cover. Overall, the classification accuracy is $80 \%$ and the Kappa coefficient is 0.7145 .

Table 5. Error matrix between two classified images.

\begin{tabular}{cccccccc}
\hline \multicolumn{7}{c}{ ERROR MATRIX (MULTISPECTRAL VS. PANSHARPENED) } \\
\hline & WATER & FOREST & GRASSLAND & AG. LAND & URBAN (S) & URBAN (D) \\
\hline WATER & 14 & 0 & 0 & 0 & 0 & $1^{*}$ & 15 \\
FOREST & 0 & 1 & 0 & 0 & 0 & 0 & 1 \\
GRASSLAND & 0 & 0 & 37 & $3^{*}$ & 0 & $16^{*}$ & 56 \\
AG. LAND & 0 & 0 & $1^{*}$ & 81 & $1^{*}$ & $9^{*}$ & 92 \\
URBAN (S) & 0 & 0 & 0 & 0 & 6 & 0 & 6 \\
URBAN (D) & $1^{*}$ & 0 & $1^{*}$ & $4^{*}$ & $3^{*}$ & 21 & 30 \\
\hline & 15 & 1 & 39 & 88 & 10 & 47 & $\mathbf{2 0 0}$ \\
\hline
\end{tabular}

$*=$ Missed classified pixels

Table 6. Accuracy assessment and Kappa statistics of two classified images.

\begin{tabular}{|c|c|c|c|c|c|c|}
\hline \multicolumn{7}{|c|}{ ACCURACY ASSESSMENT AND KAPPA $\left(\mathrm{K}^{\wedge}\right)$ STATISTICS (MULTISPECTRAL VS. PANSHARPENED) } \\
\hline & Reference & Classified & Number & Producer's & User's & KAPPA $\left(K^{\wedge}\right)$ \\
\hline & Totals & Totals & Correct & Accuracy & Accuracy & STATISTICS \\
\hline WATER & 15 & 15 & 14 & $93 \%$ & $93 \%$ & 0.9279 \\
\hline FOREST & 1 & 1 & 1 & $100 \%$ & $100 \%$ & 1.0000 \\
\hline GRASSLAND & 39 & 56 & 37 & $95 \%$ & $66 \%$ & 0.5785 \\
\hline AG. LAND & 88 & 92 & 81 & $92 \%$ & $88 \%$ & 0.7865 \\
\hline URBAN (S) & 10 & 6 & 6 & $60 \%$ & $100 \%$ & 1.0000 \\
\hline \multirow[t]{2}{*}{ URBAN (D) } & 47 & 30 & 21 & $45 \%$ & $70 \%$ & 0.6078 \\
\hline & 200 & 200 & 160 & & & \\
\hline \multicolumn{7}{|c|}{ Producer's Accuracy $=($ Number Correct $/$ Reference Total $* 100)$} \\
\hline \multicolumn{7}{|c|}{ User's Accuracy = (Number Correct / Classified Total * 100) } \\
\hline \multicolumn{7}{|c|}{ Overall Classification Accuracy $=80.00 \%$} \\
\hline \multicolumn{7}{|c|}{ Overall Kappa Statistic $=0.7145$} \\
\hline
\end{tabular}

As regards accuracy assessment by spatial pattern and contiguity approaches, Figure 8 shows the regression analysis result of local Anselin Moran's I and Z scores for two classified images. 


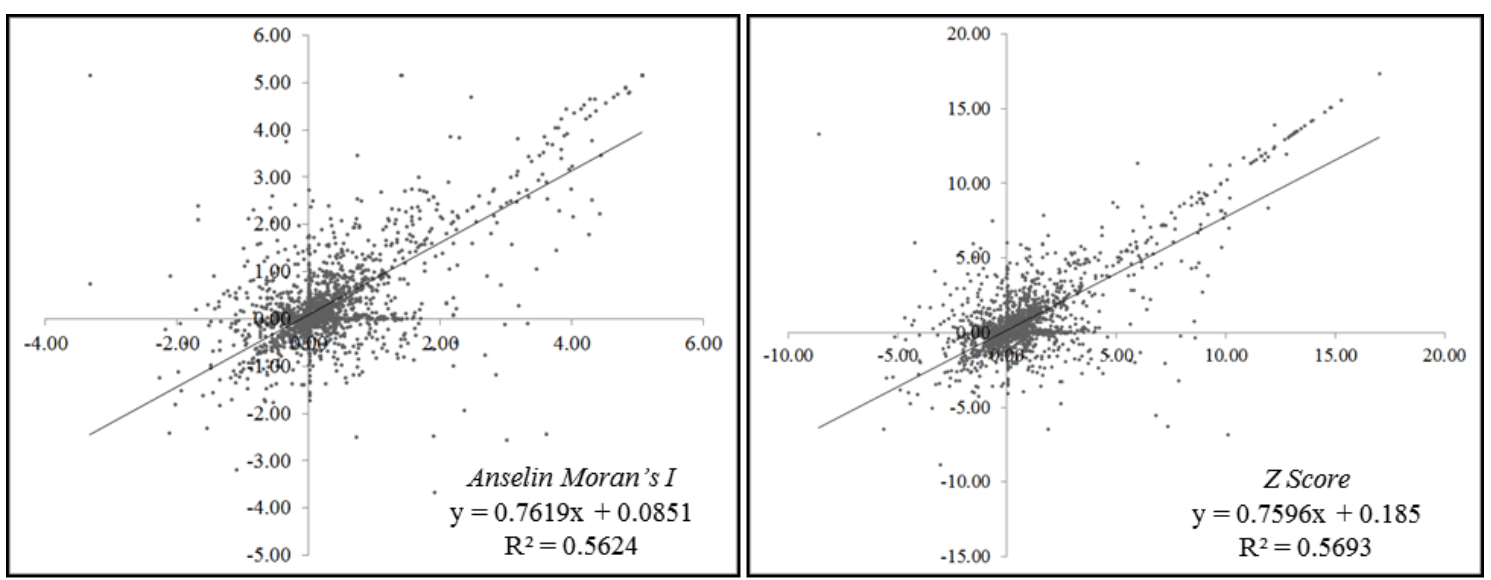

Figure 9. Regression analysis of Anselin Local Moran's I and Z score for multispectral and pansharpened images.

Although high accuracy values were seen in the Kappa coefficient analysis, above $80 \%$ for both classified images, the image differencing and Anselin Local Moran's Index regression analysis results showed that only $65 \%$ of the area has similar land cover classes and $35 \%$ has dissimilar land cover classes. Therefore, we can expect about $35 \%$ of the dissimilar land cover classes to be identified from pansharpened classified image. This percentage may vary, however, as regards the land cover types classified. For example, massive land cover types such as forest, water surfaces and agricultural land may show more similarity and urban dense, urban sparse and grassland may show more dissimilarity in both classified images (Figure 5). Based on the Anselin Local Moran's I and Z score, the $\mathrm{R}^{2}$ was 0.5624 for I and 0.5693 for the Z score. Therefore only half of the land cover has similar spatial distribution patterns and associated attribute information.

\section{Conclusion}

Delineation of human settlement areas by Landsat ETM+ pansharpened images is more promising than when using non-pansharpened multispectral images, especially in South-East Asia's cities. Although there are other high- or moderate-resolution earth resource satellites such as ALOS, SPOT, IRS, and so on, it is sometimes difficult to extract images of built-up or human settlement areas because of the lack of shortwave infrared bands which significantly help distinguish between soil and vegetation. Moreover, higher spatial resolution may introduce other unnecessary characteristics, such as trees and buildings. These high spatial resolution satellite images are typically suitable for object-oriented classification but not for multispectral per-pixel classification. ALOS AVNR-2 images, however, are suitable for studying vegetation intensity, especially urban green space, because of their favorable resolution at $10 \mathrm{~m}$ with a near infrared band which is suitable for distinguishing between green space and non-green space 
(Lwin and Murayama 2011). We are continuing to work on fine scale population mapping by integrating remote sensing and GIS data for developing countries where fine scale population maps are absent. Among the resource satellites, Landsat is the only one which has continuously captured the Earth for four decades and made an important contribution to studies of land cover change and geomorphological processes. The Landsat Data Continuity Mission (LDCM) (Landsat 8) launched on 11 February 2013 is the next satellite in the Landsat series and will continue to obtain valuable data and imagery for use in agriculture, education, business, science, and government.

\section{Acknowledgments}

\section{References}

Anselin, L. 1995. "Local Indicators of Spatial Association-LISA," Geographical Analysis 27: 93-115.

Brown, J. F., B. D. Wardlow, T. Tadesse, M. J. Hayes, and B. C. Reed. 2008. "The vegetation drought response index (VegDR): a new integrated approach for monitoring drought stress in vegetation," GIScience and Remote Sensing 45 (1): 16-46.

Cheng, J., and I. Masser. 2003. "Urban growth pattern modeling: A case study of Wuhan city, PR China," Landscape and Urban Planning 62 (4): 199-217.

Foody, G.M. 1992. "On the compensation for chance agreement in image classification accuracy assessment," Photogrammetric Engineering and Remote Sensing 58 (10): 1459-1460.

Haack, B. N., and N. D. Herold. 2007. "Comparison of Sensor Fusion Methods for Land Cover Delineations," GIScience \& Remote Sensing 44 (4): 305-319.

Jensen, J. R., and D. C. Cowen. 1999. "Remote sensing of urban/suburban infrastructure and socio-economic attributes," Photogrammetric Engineering \& Remote Sensing 65 (5): 611-622.

Jensen, R., J. Gatrell, J. Boulton, and B. Harper. 2004. "Using remote sensing and geographic information systems to study urban quality of life and urban forest amenities," Social Science Quarterly 9(5), 5-15.

Joseph, M., L. Wang, and F. Wang. 2012. "Using Landsat Imagery and Census Data for Urban Population Density Modeling in Port-au-Prince, Haiti," GIScience \& Remote Sensing 49 (2):

Kennaway, T., and E.H. Helmer. 2007. "The Forest Types and Ages Cleared from Land Development in Puerto Rico," GIScience \& Remote Sensing 44 (4): 356-382.

Kit, O., Lüdeke, M., and D. Reckien. 2012. "Texture-based identification of urban slums in Hyderabad, India using remote sensing data," Applied Geography 32 (2): 660-667. 
Klonus S., and M. Ehlers. 2007. "Image fusion using the Ehlers spectral characteristics preservation algorithm," GIScience and Remote Sensing 44 (2): 93-116.

Kohli, D., R. Sliuzas, N. Kerle, and A. Stein. 2012. "An ontology of slums for image based classification,” Computers, Environment and Urban Systems 36 (2); 154-163.

Liu, X., and M. Herold. 2006. "Population estimation and interpolation using remote sensing." In Urban remote sensing, edited by Q. Weng and D. A. Quattrochi, 269-290. Boca Raton, FL: CRC Press.

Lu, D., and Q. Weng. 2007. "A Survey of Image Classification Methods and Techniques for Improving Classification Performance," International Journal of Remote Sensing 28: 823-870.

Lwin, K.K., and Y. Murayama. 2011. " Modelling of urban green space walkability: Ecofriendly walk score calculator,” Computers, Environment and Urban Systems 35 (5): 408-420.

Mao, Y., A. Ye, and J. Xu. 2012. "Using Land Use Data to Estimate the Population Distribution of China in 2000," GIScience \& Remote Sensing 49 (6).

Mitchell, M., and Y. Fei. 2010. "Assessing Forest Fire and Vegetation Recovery in the Black Hills, South Dakota," GIScience \& Remote Sensing 47 (2).

Nichol, J. E., and M. S. Wong. 2006. "Assessing urban environmental quality with multiple parameters." In Urban remote sensing, edited by Q. Weng and D. A. Quattrochi , 253-268. Boca Raton, FL: CRC Press.

Nikolakopoulos, K.. 2003. Comparative study of fusing ETM data with five different techniques for the broader area of Pyrgos, Greece, Proceedings of SPIE, 5238:84-95 08-12 September, Barcelona, Spain.

Phinn, S. R., M. Stanford, P. Scarth, A. T. Murray, and P. T. Shyy. 2002. "Monitoring the composition of urban environments based on the vegetation-impervious surface-soil (VIS) model by subpixel analysis techniques," International Journal of Remote Sensing 23 (20): 41314153.

Pontius, R. G., and M. Millones. 2011. "Death to Kappa: birth of quantity disagreement and allocation disagreement for accuracy assessment," International Journal of Remote Sensing 32 (15): 4407-4429.

Rashed, T., J. Weeks, H. Couclelis, and M. Herold. 2007. "An integrative GIS and remote sensing model for place-based urban vulnerability analysis." In Integration of GIS and remote sensing, edited by V. Mesev, 199-233). John Wiley.

Story, M., and R. G. Congalton. 1986. "Accuracy assessment: A user's perspective," Photogrammetric Engineering \& Remote Sensing 52: 397-399.

Taubenböck, H., M. Wegmann, C. Berger, M. Breunig, A. Roth, and H. Mehl. 2008. "Spatiotemporal analysis of Indian mega cities," Proceedings of the International Archives of the Photogrammetry, Remote Sensing and Spatial Information Sciences, XXXVII (Part B2): 7581.

Vaiopoulos, D., N. Konstantinos, and G.A. Skianis. 2001. “A comparative study of resolution 
merge techniques and their efficiency in processing images of urban areas," Proceedings of the IEEE/ISPRS Joint Workshop on Remote Sensing and Data Fusion over Urban Areas, Rome, Italy, 08-09 November, pp. 270-274.

Ward, D., S. R. Phinn, and A. T. Murray. 2000. "Monitoring growth in rapidly urbanizing areas using remotely sensed data," The Professional Geographer 52 (3): 371-386.

Weeks, J. R., A. G. Hill, D. Stow, A. Getis, and D. Fugate. 2007. "Can we spot a neighborhood from the air? Defining neighborhood structure in Accra, Ghana," GeoJournal 69 (1-2): 9-22.

Wu, C., and A. T. Murray. 2005. "A cokriging method for estimating population density in urban areas," Computers, Environment and Urban Systems 29 (5): 558-579.

Yuan, F., C. Wu, and M. Bauer. 2008. "Comparison of spectral analysis techniques for impervious surface estimation using Landsat imagery," Photogrammetric Engineering and Remote Sensing 74 (8): 1045-1055.

Zhang, Y. 2004. "Understanding image fusion", Photogrammetric Engineering \& Remote Sensing 70 (6): 657-661. 